\title{
Synthetic Antigen from a Peptide Library Can Be an Effective Positive Control in Immunoassays for the Detection and Identification of Two Geminiviruses
}

\author{
A. Ziegler, M. A. Mayo, and L. Torrance
}

Virology Department, Scottish Crop Research Institute, Invergowrie, Dundee DD2 5DA, Scotland, United Kingdom. Accepted for publication 13 September 1998.

\begin{abstract}
Ziegler, A., Mayo, M. A., and Torrance, L. 1998. Synthetic antigen from a peptide library can be an effective positive control in immunoassays for the detection and identification of two geminiviruses. Phytopathology 88: 1302-1305.

Phage-displayed peptides were selected from the Cys 1 random phage display peptide library that bound strongly to the monoclonal antibody

linked immunosorbent assays and dot blot immunoassays. UV irradiation that eliminated phage infectivity did not greatly alter the antigenicity. Peptides displayed on phage are quick and cheap to prepare, and preparations can be standardized to ensure comparability among different assays. The peptide library approach can be readily extended for use with other MAbs to obtain inexpensive and safe standardized positive control reagents for use in immunoassays to diagnose plant disease.
\end{abstract} (MAb) SCR 20. The binding peptides were fused to the N-terminus of the phage protein pVIII. Preparations of the phage were shown to be effective as controls for the functionality of the SCR 20 MAb in both enzyme-
Additional keywords: ACMV, mimotope, TYLCV.
Monitoring plants for virus infection is essential to detect and eliminate viruses from germ plasm collections or propagation material and to comply with regulations governing classification schemes or the provision of plant health passports. Such tests are done routinely by enzyme-linked immunosorbent assays (ELISA) that use either polyclonal or monoclonal antibodies $(18,19)$. Antibodies specific for many economically important plant viruses can be purchased from commercial companies or obtained from research laboratories. By their nature, antibodies differ from preparation to preparation. Thus, to ensure comparability of tests done in different laboratories or at different times, defined reagents should be used, and positive and negative controls must be included in testing protocols. Infected plant material or purified virus preparations have been used as positive controls, but their distribution as a component of test kits may be difficult because of their limited stability or may be prohibited by quarantine authorities because of the risk of disseminating virus diseases. Furthermore, standardization of batches of infected plant samples is difficult to achieve. Therefore, alternative forms of positive controls are needed.

In recent years, random peptide libraries displayed on phage have been shown to be a powerful tool for identifying peptide and nonpeptide epitopes recognized by monoclonal antibodies (MAbs) (1, 14). These random peptide libraries have been constructed by fusing peptides to the coat proteins (e.g., pIII, pVIII) $(5,11,14)$ of filamentous phages. Phage clones that display peptides that bind to a MAb can be selected by successive rounds of enrichment on immobilized MAb $(11,13)$, and the sequence of the selected peptides can be determined from the DNA contained in the phage particles. Such a phage-displayed epitope would provide a convenient and precisely defined positive control reagent and, at the same time, carry no risk of the dissemination of plant disease.

Leaf curl and yellow leaf curl diseases cause economically significant crop losses in tomatoes. The causal agent is commonly called tomato yellow leaf curl virus (TYLCV), but the disease may

Corresponding author: L. Torrance; E-mail address: 1torra@scri.sari.ac.uk

Publication no. P-1998-1020-01R

(C) 1998 The American Phytopathological Society be caused by more than one virus $(4,9)$. In many countries, TYLCV is nonindigenous and virus cultures can be maintained only by graft transmission under license in special glasshouse facilities. It is, therefore, costly, both in manpower and facilities, to maintain the TYLCV strains needed for use as positive controls. MAb SCR 20 was raised from mice immunized with African cassava mosaic virus (ACMV), but it is equally effective in the detection of TYLCV (9) and is supplied as part of a commercial kit for TYLCV detection (Adgen Ltd., Ayr, United Kingdom). In this paper, we report the selection of phage-displayed peptides that bind strongly to MAb SCR 20 and thus mimic epitopes on TYLCV and ACMV particles. These phage preparations provide an adequate substitute for TYLCV or ACMV preparations as controls in ELISA testing for the presence of either virus.

\section{MATERIALS AND METHODS}

Monoclonal antibody. Preparations of MAb SCR 20 immunoglobulins $(\mathrm{IgG})$ were obtained by ammonium sulfate precipitation from ascitic fluid (17).

Peptide library. The Cys 1 library was obtained from G. Smith (University of Missouri, Columbia) as a suspension of phage particles. In this library, 13-mer random peptides are displayed at the $\mathrm{N}$-terminus of the major phage coat protein pVIII. The coding sequences used were designed such that the central amino acid of each peptide was flanked by cysteine so as to constrain the conformations that the peptides can adopt. The library was amplified by culturing infected Escherichia coli TG-1 cells overnight at $37^{\circ} \mathrm{C}$ in $100 \mathrm{ml}$ of Luria-Bertani broth (LB) supplemented with tetracycline $(12.5 \mu \mathrm{g} / \mathrm{ml})$. Phage particles were harvested by polyethylene glycol (PEG)/ $\mathrm{NaCl}$ precipitation (12).

Selection from phage library. Phage clones were obtained from the library after three successive rounds of selection against MAb preparations bound to a solid phase. Each round of selection was as follows: immunotubes (Maxisorp; Nunc, Roskilde, Denmark) were coated by treatment with $5 \mu \mathrm{g}$ of SCR $20 \mathrm{IgG}$ in $1 \mathrm{ml}$ of $0.1 \mathrm{M}$ carbonate buffer $\mathrm{pH} 9.6$ (coating buffer). An aliquot of the phage preparation was added to the coated tube (= input) and allowed to react at room temperature $\left(\approx 22^{\circ} \mathrm{C}\right)$. After washing, bound phage 
were eluted with $100 \mathrm{mM}$ triethylamine and used to infect log-phase TG-1 cells. A small volume of infected cells was removed and plated on LB-tetracycline (LB-tet) plates to establish the number of eluted phage (= output). The culture of infected TG-1 cells was grown overnight at $37^{\circ} \mathrm{C}$, and phage were precipitated by the addition of PEG/NaCl. The titer of the phage preparation was determined by infecting TG-1 cells and recording the number of tetracyclineresistant colonies that grew on LB-tet plates.

Identification of reactive phage clones. Single tetracyclineresistant colonies from the third round of selection were inoculated to $5 \mathrm{ml}$ of LB-tet and grown at $37^{\circ} \mathrm{C}$ with shaking for $18 \mathrm{~h}$. Cells were removed by centrifugation, and the culture supernatant fluid (SN) was assayed by ELISA. ELISA plates (Immunoplate II; Nunc) were coated at $4^{\circ} \mathrm{C}$ overnight with $100 \mu$ lof SCR $20 \mathrm{MAb}$ at a concentration of $2.5 \mu \mathrm{g} / \mathrm{ml}$ in coating buffer. Excess antibody was removed, and wells were blocked by adding $200 \mu$ of phosphatebuffered saline (PBS) containing 2\% nonfat dried milk (MPBS) to each well for $30 \mathrm{~min}$ at $30^{\circ} \mathrm{C}$. Plates were then washed by rinsing three times in PBS containing 0.05\% Tween-20 and once in PBS. Twenty-five microliters of MPBS was then pipetted into each well together with $75 \mu \mathrm{l}$ of $\mathrm{SN}$ containing phage particles. The plate was incubated for $4 \mathrm{~h}$ at $30^{\circ} \mathrm{C}$ and, after washing as above, $100 \mu \mathrm{l}$ of a mixture of a rabbit anti-M13 polyclonal antiserum (1:500) (21) and anti-rabbit IgG alkaline phosphatase (AP) conjugate (1:10,000; A3687; Sigma Chemical Co., Dorset, United Kingdom) were added to the wells. After incubation for $1 \mathrm{~h}$ at $30^{\circ} \mathrm{C}$, plates were washed and incubated with substrate $(0.5 \mathrm{mg}$ of $p$-nitrophenylphosphate [Sigma Chemical Co.] per $\mathrm{ml}$ of $0.1 \mathrm{M}$ diethanolamine buffer, $\mathrm{pH} 9.8$ ).

Nucleotide sequencing. Phage particles were PEG-precipitated from SN, and single-stranded phage DNA was extracted by phenolchloroform treatment (12). Sequencing was done using an ABI PRISM dye primer cycle sequencing ready reaction kit (PerkinElmer Applied Biosystems, Warrington, United Kingdom). The primer was complementary to DNA encoding the phage coat protein pVIII gene, downstream of the peptide insert. Sequences were analyzed using the Genetics Computer Group package (3).

Surface plasmon resonance (SPR). SPR studies were done using a BIACORE X instrument (Biacore AB, Uppsala, Sweden), and the results were analyzed by using BIAevaluation (software version 3 [supplied with the instrument]; Biacore $\mathrm{AB}$ ). The system buffer was $10 \mathrm{mM} N$-2-hydroxyethylpiperazine- $N^{\prime}$-2-ethanesulfonic acid, pH 7.4, containing $150 \mathrm{mM} \mathrm{NaCl}, 3.4 \mathrm{mM}$ EDTA, and $0.005 \%$ surfactant P20 (Biacore AB) (HBS). The flow rate was $5 \mu \mathrm{l} / \mathrm{min}$.

Phage particles were coupled to the dextran matrix of a CM5 sensor chip (Biacore $\mathrm{AB}$ ) by the ligand thiol coupling method, following the manufacturer's instructions. The dextran surface of both flow cells was modified by injecting $10 \mu \mathrm{l}$ of $0.05 \mathrm{M} \mathrm{N}$-hydroxysuccinimide and $0.2 \mathrm{M} \mathrm{N}$-ethyl- $N^{\prime}$-(dimethylaminopropyl) carbodiimide, followed by $20 \mu \mathrm{l}$ of $80 \mathrm{mM}$ 2-(2-pyridinyldithio)ethaneamine hydrochloride in $0.1 \mathrm{M}$ borate buffer, $\mathrm{pH} 8.5$. A preparation of recombinant phage particles was diluted to $10^{9} / \mathrm{ml}$ in $10 \mathrm{mM}$ glycine, $\mathrm{pH} 3.0$, and $30 \mu \mathrm{l}$ was injected over flow cell 2; the same amount of control phage Cys 1.8 (randomly chosen clone from unselected library) was injected over flow cell 1 . The remaining reactive groups were blocked by injection of $20 \mu \mathrm{l}$ of $50 \mathrm{mM}$ cysteine and $1 \mathrm{M}$ $\mathrm{NaCl}$ in $0.1 \mathrm{M}$ formate buffer, $\mathrm{pH} 4.3$. Approximately 4,600 resonance units $(\mathrm{RU})$ of phage were immobilized to flow cell 1 and $5,000 \mathrm{RU}$ to flow cell 2.

A $1-\mathrm{mg} / \mathrm{ml}$ preparation of SCR $20 \mathrm{IgG}$ was diluted in HBS, and different concentrations ( 66 to $267 \mathrm{nM}$ ) were injected over the surface. Bound antibody was removed by injection of $12 \mu \mathrm{l}$ of $0.005 \%$ sodium dodecyl sulfate (SDS). Three independent experiments, each with three antibody concentrations, were done to obtain data for kinetic analysis.

Determination of optimum amount of phage for a positive control for ELISA. An ELISA plate was coated with different amounts of phage particles diluted in PBS or in coating buffer. After blocking, a mixture of MAb SCR 20 and anti-mouse AP (Sigma Chemical Co.) was added and the ELISA completed as described above.

Phage dot blot on nitrocellulose membrane. Different amounts of phage particles were pipetted onto nitrocellulose membrane (Schleicher \& Schuell, Inc., Dassel, Germany) in volumes of 1 to $10 \mu \mathrm{l}$. The membrane was air-dried and blocked in Tris-buffered saline (TBS) containing 5\% nonfat dried milk and then incubated in a mixture of MAb SCR 20 and anti-mouse AP conjugate. After washing with TBS-Tween $(0.05 \%)$, the membrane was incubated in $0.4 \mathrm{mM}$ 5-bromo-4-chloro-3-indolyl phosphate/0.4 mM nitro blue tetrazolium (Sigma Chemical Co.).

UV irradiation of phage particles. To render phage particles noninfectious, aliquots of a phage preparation $\left(2 \times 10^{10}\right.$ phage particles per $100 \mu \mathrm{l}$ of PBS) were UV-irradiated in a UV crosslinker (Stratalinker UV crosslinker; Stratagene Ltd., Cambridge, United Kingdom) at a wavelength of $254 \mathrm{~nm}$ and dose levels ranging from 10 to $800 \mathrm{~mJ} / \mathrm{cm}^{2}$. The phage particles were then used to infect log-phase TG-1 cells, and the cells were plated onto LB plates containing tetracycline. The wells of an ELISA plate were coated with the treated phage particles to test the effect of irradiation on binding of the antibody to the phage-displayed peptides.

\section{RESULTS}

Selection of phage. Decreasing numbers of phage $\left(3 \times 10^{11}, 1.8 \times\right.$ $10^{10}$, and $1 \times 10^{9}$ for first, second, and third round, respectively) were used as input in successive rounds of selection. Nevertheless, the output titer increased $\left(1.43 \times 10^{4}, 1.04 \times 10^{4}\right.$, and $5.2 \times$ $10^{4}$ ), indicating an enrichment for phage particles binding to the MAb. From the output of the third round, 24 individual tetracycline-resistant colonies were picked for testing in phage ELISA. Of the 24 clones, 22 produced particles that bound to the MAb (mean $A_{405}$ of $>1$ after $30 \mathrm{~min}$ ) compared with $A_{405}$ of $<0.1$ when the same preparations were added to wells coated with the unrelated mouse MAb 9E10 (10) at $2.5 \mu \mathrm{g} / \mathrm{ml}$. DNA from eight of the positive phage clones was extracted and sequenced. DNA was also extracted from six phage clones picked from the library before selection on MAb SCR 20. Sequences of the encoded peptides showed that the clones that bound to SCR 20 had either of two sequences that shared a motif (Fig. 1). One of the peptides (Cys 3.5) was selected three times; the other five clones contained Cys 3.7. All of the nonselected clones (e.g., Cys 1.8) differed in sequences from each other and from the clones selected on antibody-coated tubes. The amino acid sequences of Cys 3.5 and Cys 3.7 were similar, the "consensus" being xxxPxWKCxxxxx. However, sequence alignments between the peptide motifs and the coat proteins of either ACMV or TYLCV did not show any sequence identity.

SPR experiments. When MAb SCR 20 in HBS was injected over the phage particles, SCR 20 bound to phage Cys 3.5 immobilized on the dextran surface of the sensor chip, but not to the control phage Cys 1.8 (Fig. 2). The sensorgrams were analyzed by using BIAevaluation software version 3. The best fit was obtained using a bivalent interaction model and analysis using the "global" fit option but with the association rate constant fitted to each curve separately (data not shown). SCR 20 is a bivalent molecule, and using this model, it was possible to obtain the equilibrium affinity constant for the interaction $\mathrm{A} 1+\mathrm{B}$ (in which $\mathrm{A} 1$ is the monovalent binding of antibody to antigen $\mathrm{B}$ ). In these experi-

\section{Cys 3.5 G H A P S W K C Q L H H T \\ Cys 3.7 H G R P P W K C D Q P R P \\ Cys 1.8 N Q Q A H C N C P V L P P}

Fig. 1. Peptide motifs of the selected phages Cys 3.5 and Cys 3.7 and of the unrelated phage Cys 1.8. 


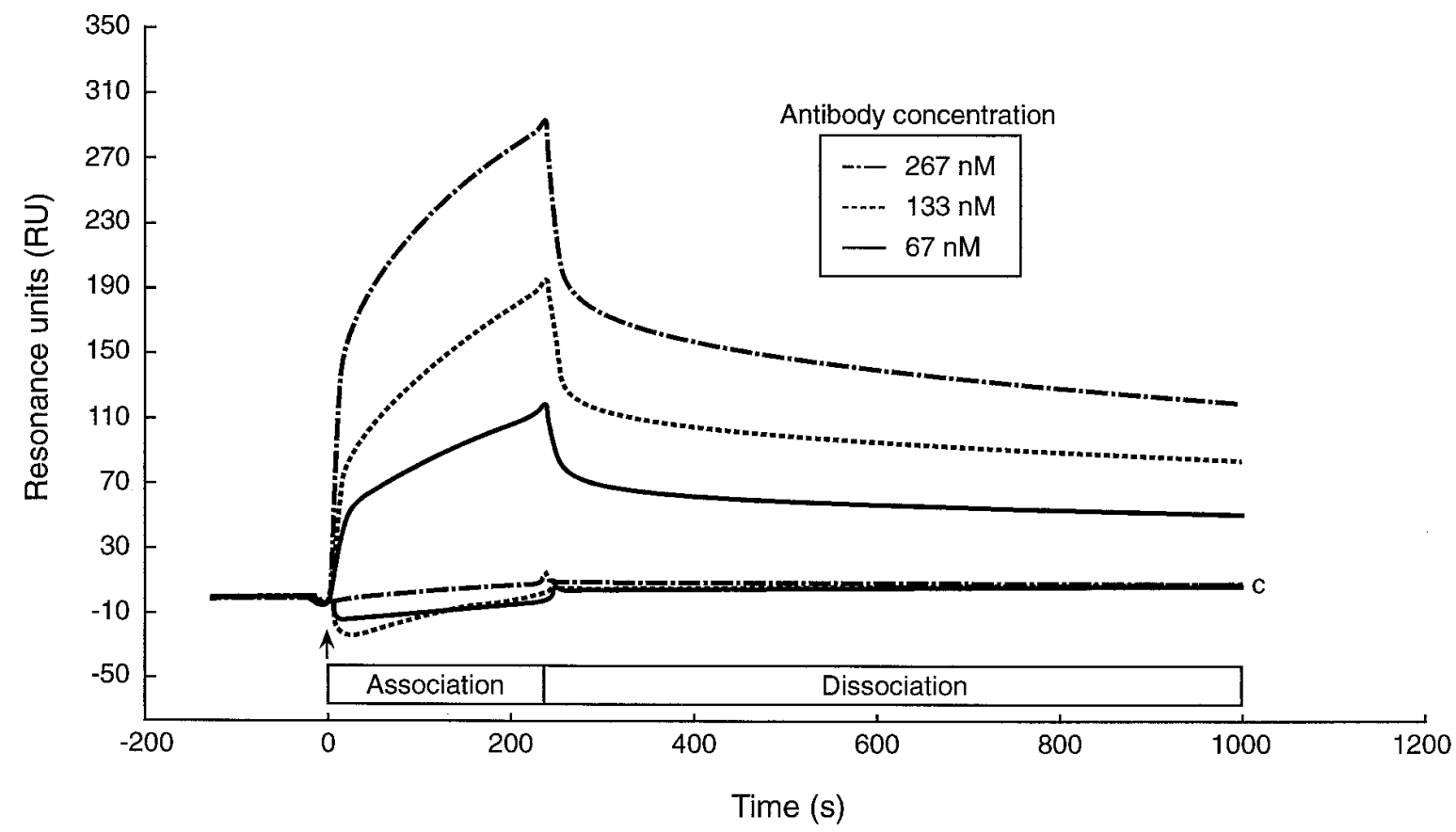

Fig. 2. Sensorgrams of monoclonal antibody SCR 20 binding to phage Cys 3.5. SCR 20 was tested at 67, 133, and $267 \mathrm{nM}$. The start of the injection (arrowed) and the association and dissociation phases are indicated. Negligible binding to the unrelated phage Cys 1.8 is shown by the three lower curves collectively labeled "c."

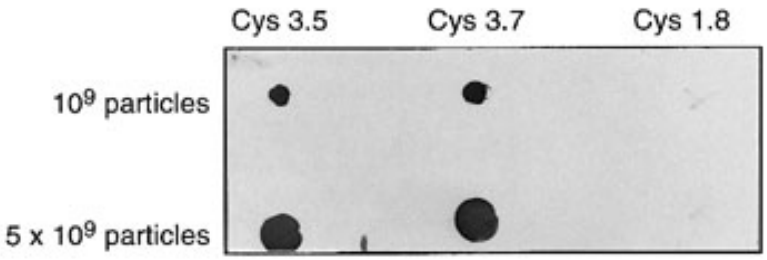

Fig. 3. Detection of immobilized phage particles on nitrocellulose membrane.

ments, the equilibrium affinity constant was found to be $3.47 \pm$ $0.46 \times 10^{6} \mathrm{M}^{-1}$.

Optimum number of phage. ELISA tests were made using plates coated with different amounts of phage particles to establish how many particles were needed to give a sufficient signal $\left(A_{405}\right.$ of around 1$)$. The best results were obtained when $10^{9}$ phage particles were added to each well to coat the ELISA plates. The reaction was readily detectable with the MAb SCR 20 after $1 \mathrm{~h}$ of incubation with substrate $\left(A_{405}=1.2\right)$. Coating with $10^{9}$ particles of the control, unrelated phage clone Cys 1.8, gave an $A_{405}$ of $<0.1$.

In comparison, using the same ELISA conditions, an extract of ACMV-infected tomato leaf gave an $A_{405}$ of 1.2 and that of TYLCV (isolate from Sardinia) gave an $A_{405}$ of 0.9. A similar test on tomato infected with Indian tomato leaf curl virus, which cannot be detected with SCR 20 (16), gave an $A_{405}$ of 0.08 .

Phage dot blot assay. The MAb SCR 20 has been used to detect TYLCV by tissue printing (4). Tests were done to ascertain if the phage-expressed peptides were reactive after binding to nitrocellulose and thus could act as positive controls in such tests. A total of $10^{9}$ phage (Cys 3.5 and Cys 3.7) particles, immobilized on nitrocellulose, were readily detected by the SCR 20 MAb. Spots containing $10^{9}$ particles of Cys 1.8 , the control (unrelated) phage, did not bind SCR 20 (Fig. 3).

Effect of UV irradiation on phage infectivity. Preparations of Cys 3.5 and Cys 3.7 were infectious and, therefore, could contaminate laboratories. UV irradiation was tested as a way of avoiding this problem. Samples of phage were diluted in PBS and treated in an UV-crosslinker (Stratagene Inc.). The infectivity of Cys 3.7 for TG- 1 cells was decreased from $\approx 1,000 \mathrm{CFU}$ to $\approx 20 \mathrm{CFU}$ by irradiation at $10 \mathrm{~mJ} / \mathrm{cm}^{2}$ and abolished by irradiation at $100 \mathrm{~mJ} / \mathrm{cm}^{2}$. Ir-

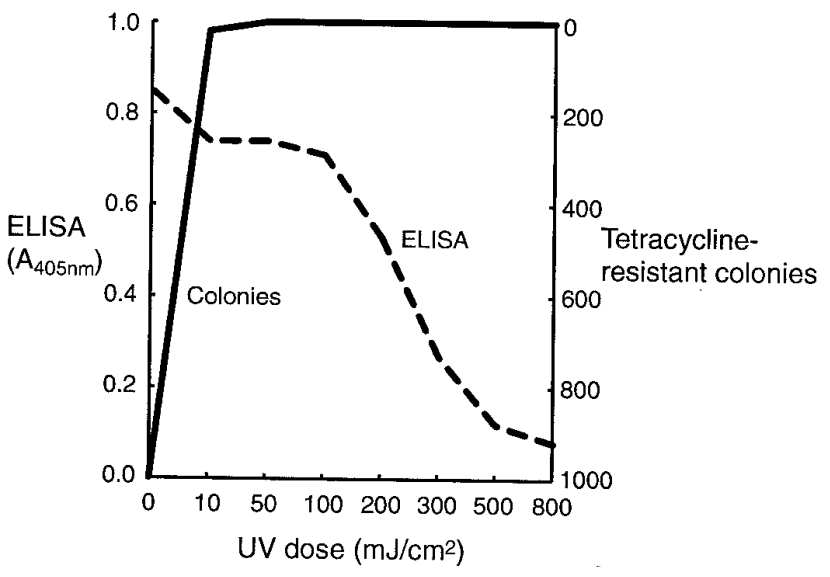

Fig. 4. Effect of UV irradiation of phage particles Cys 3.7 on infectivity and performance in enzyme-linked immunosorbent assay. $A_{405}$ was recorded after 30 min of incubation with substrate.

radiation also decreased the reactivity of phage in ELISA. Samples treated with 10,50 , or $100 \mathrm{~mJ} / \mathrm{cm}^{2}$ bound about $85 \%$ of the amount of MAb bound by untreated samples. Binding by preparations treated with 200 or $300 \mathrm{~mJ} / \mathrm{cm}^{2}$ was decreased to 60 and $30 \%$ of that by untreated phage, respectively (Fig. 4). Treatments at higher doses virtually abolished binding, probably because the peptide was damaged or crosslinked. No viable phage were detected after treatment at $100 \mathrm{~mJ} / \mathrm{cm}^{2}$, and the results of ELISA were only slightly less than control values. Therefore, this was considered to be a suitable treatment for making phage noninfectious without compromising the binding affinity.

\section{DISCUSSION}

Random peptide libraries have been widely used to study epitopes of MAbs and the epitope profiles of polyclonal antisera (1). Sometimes, the selected peptides do not contain the same amino acid sequences as the putative epitopes. These peptides are mimicking the epitope and are called mimotopes $(8,15)$. The selection 
of disease-specific mimotopes from antisera from diseased patients has been proposed as one approach to produce vaccines (7). In the work reported here, we used a random peptide library to select a peptide mimotope that binds to an anti-ACMV/anti-TYLCV MAb (SCR 20) with micromolar affinity. The measured affinity for monovalent MAb binding was moderate, and less than that of the MAb for TYLCV virus particles (nanomolar affinity calculated from competition ELISA; A. Ziegler, unpublished data). However, expression of large numbers of peptides on phage particles favors bivalent binding of MAb, which increases the functional affinity (or avidity) (20) and enhances binding, thus producing high ELISA values.

The amino acid sequences of the peptides that bound to SCR 20 were not found in the coat protein sequences of either ACMV (the homologous antigen) or TYLCV. Previously, experiments to identify the epitope of SCR 20 using the method of Geysen et al. (8) failed (16). Also, SCR 20 did not react with SDS-denatured coat protein of ACMV in immunoblot assays. These results suggest that SCR 20 reacts with a discontinuous epitope. Therefore, it is not surprising that the motif found in the selected phage-displayed peptides had no homologue in the amino acid sequences of ACMV or TYLCV coat proteins. The ability to select peptide mimotopes is an advantage of using the peptide library approach $(6,8,15)$.

The random peptides displayed on the $\mathrm{N}$-terminus of the phage coat protein pVIII were designed to contain two cysteine residues in order to introduce a conformational constraint. However, the $\mathrm{N}$ proximal cysteine in each of the peptide motifs selected by MAb SCR 20 had been substituted by a tryptophan, whereas six clones from the nonselected library sample have both cysteine residues present. The panning process apparently selected nonconstrained, linear peptide ligands that can functionally mimic the discontinuous epitope of MAb SCR 20. Since it needs only a single point mutation (UGC or UGU to UGG) to create such a substitution, we presume that the original library contained mutants with such a change, and that these were selected.

Although it is possible to use synthetic peptides instead of phagedisplayed peptides, Demangel et al. (2) showed that peptides sometimes fail to react with the antibody when they were not displayed as part of a phage protein. Also, the production of synthetic peptides is much more expensive than the preparation of quantities of phage. Live phage are a source of contamination, but the results show that phage killed by UV irradiation retain antigenicity.

In summary, the mimotopes we have selected can be used as a control for the functionality of SCR 20 MAb in both ELISA and tissue print experiments done on nitrocellulose membranes. This use of peptide libraries as sources of controls for immunoassays could be extended to other plant pathogens, especially those difficult to obtain in a form suitable for use as an immunodiagnostic control. For example, particles of some viruses are very unstable and degrade quickly (some potyviruses, beet necrotic yellow vein virus, potato mop-top virus), and others are erratically distributed in infected plants, thereby making it difficult to predict sap concentration. Also, some fungal and bacterial pathogens are difficult to obtain in defined and reproducible quantities. Thus the mimotope approach we have adopted in work with TYLCV and ACMV could be of much wider application in the diagnosis of plant pathogens.

\section{ACKNOWLEDGMENTS}

Scottish Crop Research Institute is grant-aided by SOAEFD. We thank G. Smith for providing the peptide library.

\section{LITERATURE CITED}

1. Cortese, R., Felici, F., Galfre, G., Luzzago, A., Monaci, P., and Nicosia, A. 1994. Epitope discovery using peptide libraries displayed on phage. Trends Biotechnol. 12:262-267.

2. Demangel, C., Lafaye, P., and Mazie, J. 1996. Reducing the immuneresponse against the Plasmodium-vivax merozoite surface protein-1 with mimotopes selected from a phage-displayed peptide library. Mol. Immunol. 33:909-9168.

3. Devereux, J., Haeberli, P., and Smithies, O. 1984. A comprehensive set of nucleotide sequence analysis programs for the VAX. Nucleic Acids Res. 12:387-395.

4. Fargette, D., Leslie, M., and Harrison, B. D. 1996. Serological studies on the accumulation and localization of three tomato leaf curl geminiviruses in resistant and susceptible Lycopersicon species and tomato cultivars. Ann. Appl. Biol. 128:317-328.

5. Felici, F., Castagnoli, L., Musacchio, A., Jappelli, R., and Cesareni, G. 1991. Selection of antibody ligands from a large library of oligopeptides expressed on a multivalent exposition vector. J. Mol. Biol. 222: 301-310.

6. Felici, F., Luzzago, A., Folgori, A., and Cortese, R. 1993. Mimicking of discontinuous epitopes by phage-displayed peptides. II Selection of clones recognized by a protective monoclonal antibody against the Bordetella pertussis toxin from phage peptide libraries. Gene 128:21-27.

7. Folgori, A., Tafi, R., Meola, A., Felici, F., Galfre, G., Cortese, R., Monaci, P., and Nicosia, A. 1994. A general strategy to identify mimotopes of pathological antigens using only random peptide libraries and human sera. EMBO (Eur. Mol. Biol. Organ.) J. 13:2236-2243.

8. Geysen, H. M., Rodda, S. J., Mason, T. J., Tribbick, G., and Schoofs, P. G. 1987. Strategies for epitope analysis using peptide synthesis. J. Immunol. Methods 102:259-274.

9. Macintosh, S., Robinson, D. J., and Harrison, B. D. 1992. Detection of three whitefly-transmitted geminiviruses occurring in Europe by test with heterologous monoclonal antibodies. Ann. Appl. Biol. 121:297-303.

10. Munro, S., and Pelham, H. R. B. 1986. An Hsp-like protein in the ER: Identity with the $78 \mathrm{kD}$ glucose regulated protein and immunoglobulin heavy chain binding protein. Cell 46:291-300.

11. Parmley, S. F., and Smith, G. P. 1988. Antibody-selectable filamentous fd phage vectors: Affinity purification of target genes. Gene 73:305-318

12. Sambrook, J., Fritsch, E. F., and Maniatis, T. 1989. Molecular Cloning: A Laboratory Manual. Cold Spring Harbor Laboratory Press, Cold Spring Harbor, NY.

13. Scott, J. K., and Smith, G. P. 1990. Searching for peptide ligands with an epitope library. Science 249:386-390.

14. Smith, G. P. 1991. Surface presentation of protein epitopes using bacteriophage expression systems. Curr. Opin. Biotechnol. 2:668-673.

15. Stephen, C. W., Helminen, P., and Lane, D. P. 1995. Characterization of epitopes on human p53 using phage-displayed peptide libraries: Insights into antibody-peptide interactions. J. Mol. Biol. 248:58-78.

16. Swanson, M. M. 1991. Antigenic variation and serological relationships of whitefly-transmitted geminiviruses. Ph.D. thesis. University of Dundee, Dundee, Scotland.

17. Thomas, J. E., Massalski, P. R., and Harrison, B. D. 1986. Production of monoclonal antibodies to african cassava mosaic virus and differences in their reactivities with other whitefly-transmitted geminiviruses. J. Gen. Virol. 67:2739-2748.

18. Torrance, L. 1992. Serological methods to detect plant viruses: Production and use of monoclonal antibodies. Pages 7-33 in: Techniques for the Rapid Detection of Plant Pathogens. J. M. Duncan and L. Torrance, eds. Blackwell Scientific Publications, Oxford.

19. Torrance, L. 1995. Use of monoclonal antibodies in plant pathology. Eur. J. Plant Pathol. 101:351-363.

20. Van Regenmortel, M. H. V. 1992. Molecular dissection of protein antigens. Pages 1-27 in: Structure of Antigens. M. H. V. Van Regenmortel, ed. CRC Press, Boca Raton, FL.

21. Ziegler, A., Torrance, L., Macintosh, S. M., Cowan, G. H., and Mayo, M. A. 1995. Cucumber mosaic cucumovirus antibodies from a synthetic phage display library. Virology 214:235-238. 